\title{
Predicting anticoagulant-related bleeding in patients with venous thromboembolism: a clinically oriented review
}

\author{
Frederikus A. Klok ${ }^{1}$, Judith Kooiman², Menno V. Huisman² \\ Stavros Konstantinides ${ }^{1}$ and Mareike Lankeit ${ }^{1}$
}

Affiliations:

${ }^{1}$ Center for Thrombosis and Hemostasis (CTH), University Medical Center Mainz, Mainz, Germany.

${ }^{2}$ Dept of Thrombosis and Hemostasis, Leiden University Medical Center, Leiden, The Netherlands.

\section{Correspondence:}

Frederikus A. Klok, Center for Thrombosis and Hemostasis (CTH), University Medical Center Mainz, Langenbeckstr. 1, 55131 Mainz, Germany.

E-mail: Frederikus.Klokdunimedizin-mainz.de

ABSTRACT Diagnosis of venous thromboembolism (VTE) requires prompt treatment with anticoagulants in therapeutic doses. Since these drugs are associated with the occurrence of haemorrhage, identification of patients at increased risk of major bleeding is of utmost clinical importance for defining the optimal treatment regimen and duration of anticoagulation. Current suggested prediction scores for bleeding risk in VTE patients have been derived from observational studies of moderate quality, or from patients with various indications for therapeutic anticoagulation other than VTE. To date, none of the scores have been adequately validated in cohorts that underwent dedicated monitoring and independent adjudication of bleeding complications. In addition, while the scarce available evidence has focused on patients treated with heparins and/or vitamin $\mathrm{K}$ antagonists, risk stratification scores for bleeding complications in VTE patients treated with non-vitamin $\mathrm{K}$ dependent anticoagulants have not yet been developed. This clinically oriented review covers the incidence and risk factors of anticoagulation-related bleeding in VTE patients treated with different anticoagulant drugs as well as the available bleedingprediction scores. Further, we attempt to provide guidance for bleeding-prevention in clinical practice and speculate on developments in the near future that may fundamentally change our current thinking on VTE management.

@ERSpublications

Bleeding in VTE: no validated risk-prediction scores, no effective preventive measures: are NOACs the solution? http://ow.ly/zjBzl 


\section{Introduction}

Venous thromboembolism (VTE), which encompasses deep vein thrombosis (DVT) and acute pulmonary embolism (PE), requires prompt treatment with therapeutically dosed anticoagulants to prevent progressive disease which might result in serious morbidity or death. The minimum recommended treatment duration is 3 months, although this period may be extended to 6 months or even an indefinite period, depending on the patient's individual risk profile $[1,2]$.

Traditionally, the anticoagulant regimen consists of low molecular weight heparin (LMWH), fondaparinux, or unfractionated heparin (UFH) while awaiting therapeutic international normalised ratio (INR) levels under overlapping administration of vitamin $\mathrm{K}$ antagonists (VKAs) $[1,2]$. In recent years, non-vitamin $\mathrm{K}$ dependent anticoagulants (NOACs) have been developed including direct factor IIa (i.e. dabigatran) and factor Xa inhibitors (i.e. apixaban, edoxaban and rivaroxaban), which lack several of the limitations of VKA treatment such as food interactions and the need for frequent INR monitoring. The NOACs are reported to have a superior safety profile compared with VKAs for both acute as well as extended treatment of patients with VTE [3-10]. Nevertheless, even with the new generation of anticoagulant agents, the most relevant and frequent complication of anticoagulant treatment is major haemorrhage, which is notoriously associated with significant morbidity, mortality and considerable costs [11-13]. Since the need for anticoagulation therapy after an acute VTE episode is undisputable [1, 2, 14-17], assessment of the individual bleeding risk is most relevant when choosing the appropriate anticoagulant drug and treatment duration.

This clinically oriented review covers the incidence and risk factors of anticoagulation-related bleeding in VTE patients treated with different anticoagulant drugs as well as the available bleeding-prediction scores. In addition, we attempt to provide guidance for bleeding-prevention in clinical practice and speculate on developments in the near future that may fundamentally change current thinking in VTE management.

\section{Risk of bleeding}

Incidence of major bleeding during initial heparin treatment

With regard to initial treatment (first 5-10 days) with heparin in combination with a loading dose of VKA administered within $48 \mathrm{~h}$ of VTE diagnosis, several trials have compared the safety of a fixed-dose LMWH administered subcutaneously to intravenous activated partial thromboplastin time-adjusted dosed UFH. The results have been summarised in a meta-analysis with pooled data from 7124 patients: major haemorrhage occurred in $41(1.2 \%)$ out of 3500 patients treated with LMWH compared with $73(2.0 \%)$ out of 3624 patients treated with UFH (OR 0.57, 95\% CI 0.39-0.83), thus suggesting that LMWH may reduce the occurrence of major bleeding during initial treatment compared with UFH (table 1), with equal efficacy in preventing recurrent VTE [18].

\section{Incidence of major bleeding during the first months of treatment}

Bleeding episodes in the first 3 months should be considered as a distinct category from those occurring after this period. VKA-related bleeding complications were evaluated by LinkINs et al. [19] in a meta-analysis of 33 prospective studies. Within the first 3 months (including initial heparin treatment), the absolute risk of major bleeding was estimated to be $2.06 \%$ (54 out of 2422 patients; $95 \%$ CI $2.04-2.08 \%$ ) with a case-fatality rate of $9.3 \%$ (95\% CI 3.1-20\%) (table 1) [19].

According to the pooled results of five multicentre randomised controlled trials (RCTs) that compared application of the NOACs to conventional LMWH/VKA therapy for initial treatment of acute VTE, NOACs have a comparable efficacy in preventing recurrent VTE but a superior safety profile. The risk of major bleeding during the predominantly 6 -month treatment period was only $1.1 \%$ in those treated with NOACs (131 out of 12197 patients; case-fatality rate 5.3\%) (tables 1 and 2) [3-7, 20]. Notably, because strict patient selection criteria were applied, the risk of major bleeding for patients randomised to LMWH/VKA treatment was considerably lower than reported in historical studies: 1.7\% (211 out of 12193 patients; case-fatality rate $10 \%$ ). Even so, the incidence of major bleeding (pooled risk ratio $0.60,95 \%$ CI $0.41-0.88$ ) as well as fatal bleeding (pooled risk ratio $0.36,95 \%$ CI $0.15-0.87$ ) was significantly lower for patients treated with one of the NOACs [20]. The bleeding risks from the individual NOAC trials are reported in table 2. It should be noted that NOACs are either administered in an increased initial dosage (apixaban and rivaroxaban), or after initial treatment with parenteral anticoagulants for at least 5 days (edoxaban and dabigatran) [3-8]. Bleeding risk during the first 10 days after treatment initiation were not consistently reported in the NOAC trials.

\section{Incidence of major bleeding during continued treatment}

After the first 3 months, the rate of VKA-associated major bleeding was estimated to be 2.74 per 100 patient-years (44 out of 2422 patients over a period ranging between 3 and 9 months; 95\% CI 2.71-2.77\%) with a comparable case-fatality rate of $9.1 \%$ (95\% CI 2.5-22\%) (table 1) when compared to the first 3 months of treatment [19]. When considering VKA-treatment of VTE patients regardless of the time-point of occurrence, 
TABLE 1 Risk of anticoagulant-related bleeding in patients with venous thromboembolism according to treatment phase

\begin{tabular}{|c|c|c|c|}
\hline Treatment period & VKA & $\begin{array}{l}\text { LMWH (patients } \\
\text { with cancer) }\end{array}$ & NOAC \\
\hline $\begin{array}{l}\text { Initial treatment in the first } 5-10 \text { days } \\
\text { (case-fatality rate \%) }\end{array}$ & $1.2 \%^{\#}\left(0-40 \%{ }^{\top}\right)$ & Not reported & Not reported in general for all NOACs \\
\hline $\begin{array}{l}\text { Treatment in the first } 3 \text { months } \\
\text { (case-fatality rate \%) }\end{array}$ & $2.1 \%(9.3 \%)$ & $3.3-7.0 \%$ ๆ $(0-17 \%$ ๆ) & Not reported in general for all NOACs \\
\hline Extended treatment (case-fatality rate \%) & $\begin{array}{c}2.74 \text { per } 100 \\
\text { patient-years }(9.1 \%)\end{array}$ & Not reported & $\begin{array}{c}0.1-0.9 \% \text { in } 6-12 \text { months following } \\
\text { an initial treatment period of } \\
6-12 \text { months }{ }^{\pi}(0-4 \% \text { ) }\end{array}$ \\
\hline Total treatment period (case-fatality rate \%) & $\begin{array}{l}7.22 \text { per } 100 \\
\text { patient-years }(13.4 \%)\end{array}$ & $\begin{array}{l}5.6-9.3 \% \text { in first } 6 \\
\text { months }{ }^{ף}(0-5 \% \text { ? })\end{array}$ & $1.1 \%$ in first $6-12$ months $(5.3 \%)$ \\
\hline
\end{tabular}

VKA: vitamin $\mathrm{K}$ antagonist; LMWH: low molecular weight heparin; NOAC: non-vitamin K dependent anticoagulants. "\#: LMWH and VKA loading dose; ${ }^{\text {ๆ: }}$ data not pooled in meta-analysis.

\begin{abstract}
an analysis of 10757 patients estimated that major VKA-associated bleeding occurred at a rate of 7.22 per 100 patient-years (95\% CI 7.19-7.24) with a case-fatality rate of 13.4\% (95\% CI 9.4-17.4\%) (table 1) [19].

Four RCTs have assessed the efficacy and safety of NOACs in an extended treatment period [4, 9, 10]. Although not summarised in a meta-analysis, these four trials showed that rivaroxaban, apixaban and dabigatran are all effective in preventing recurrent VTE (hazard ratio ranging between 0.08 and 0.36 ) when compared with placebo, at the cost of only a few major bleeding complications (table 3) $[4,9,10]$. In addition, dabigatran was directly compared with warfarin in extended treatment [9]. Recurrent VTE occurred in $1.8 \%$ of the patients in the dabigatran group compared with $1.3 \%$ in the warfarin group (hazard ratio 1.4, 95\% CI 0.78 2.6), which was within the predefined limits for noninferiority. Major bleeding occurred in $0.9 \%$ of patients in the dabigatran group and in $1.8 \%$ in the warfarin group (hazard ratio $0.52,95 \%$ CI $0.27-1.02$ ) (table 3 ).
\end{abstract}

\title{
Incidence of major bleeding during treatment of cancer-associated VTE
}

Patients with cancer-associated VTE have an increased risk of both VTE recurrence and anticoagulant-related bleeding, compared with those without cancer [21]. Four different large open-label multicentre RCTs comparing LMWH with warfarin for the treatment of acute VTE in patients with cancer, each reported the rate of LMWH- versus warfarin-associated major bleeding: $7.0 \%$ (five out of 71 ; none of which were fatal) versus $3.3 \%$ (12 out of 369; two of which were fatal) in the first 3 months, and 5.6\% (19 out of 338; one of

TABLE 2 Overview of bleeding risk in the phase 3 clinical trials with non-vitamin $\mathrm{K}$ dependent anticoagulants for the initial treatment of venous thromboembolism

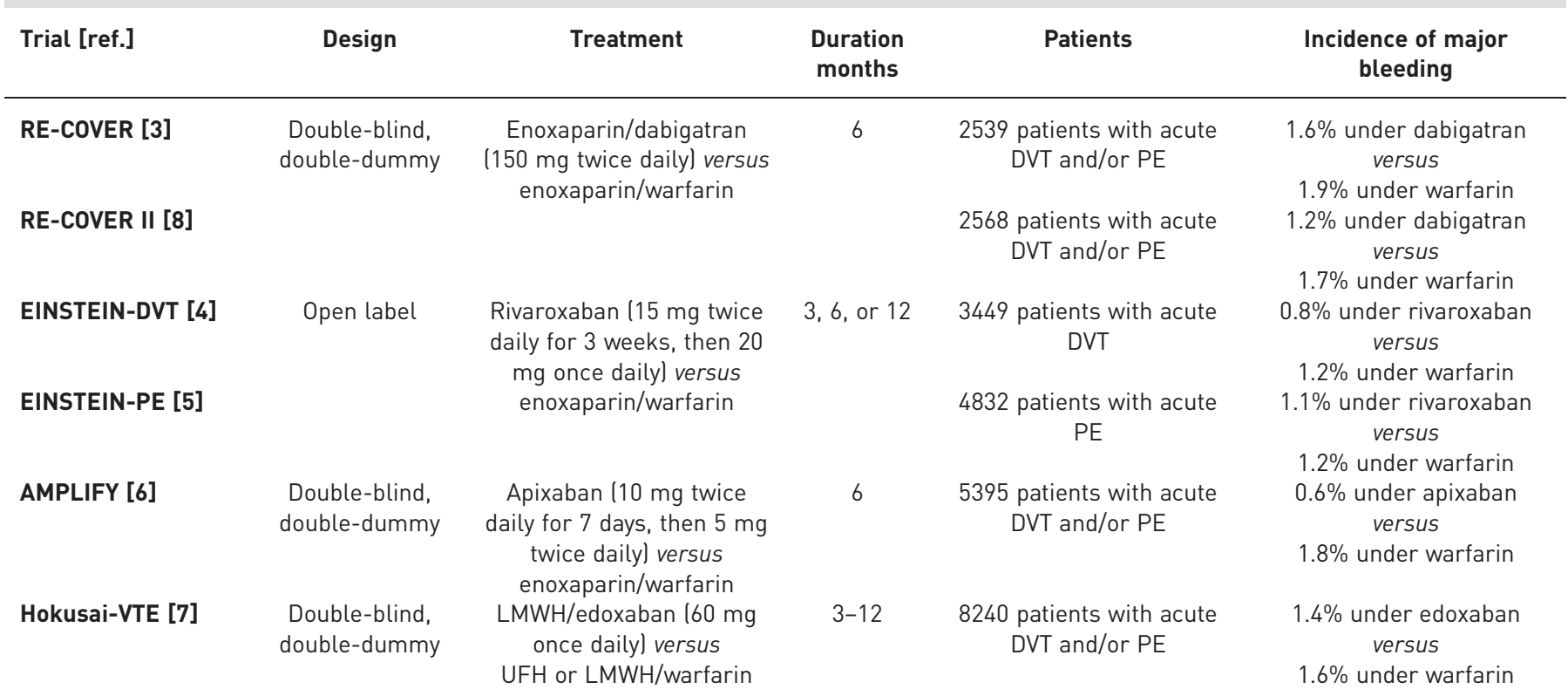

DVT: deep vein thrombosis; PE: pulmonary embolism; LMWH: low molecular weight heparin; UFH: unfractionated heparin. 
TABLE 3 Overview of bleeding risk in the phase 3 clinical trials with non-vitamin $\mathrm{K}$ dependent anticoagulants for the continued treatment of venous thromboembolism

\begin{tabular}{|c|c|c|c|c|c|}
\hline Trial & Design & Treatment & $\begin{array}{l}\text { Duration } \\
\text { months }\end{array}$ & Patients & Incidence of major bleeding \\
\hline RE-SONATE [9] & Double-blind & $\begin{array}{l}\text { Dabigatran (150 mg twice } \\
\text { daily) versus placebo }\end{array}$ & 6 & $\begin{array}{l}1343 \text { patients after } \\
\text { uneventful initial treatment } \\
\text { for acute DVT and/or PE }\end{array}$ & $\begin{array}{c}0.3 \% \text { under dabigatran versus } \\
0 \% \text { under placebo }\end{array}$ \\
\hline RE-MEDY [9] & $\begin{array}{l}\text { Double-blind, } \\
\text { double-dummy }\end{array}$ & $\begin{array}{l}\text { Dabigatran (150 mg twice } \\
\text { daily) versus warfarin }\end{array}$ & $18-36$ & $\begin{array}{l}2856 \text { patients after } \\
\text { uneventful initial treatment } \\
\text { for acute DVT and/or PE }\end{array}$ & $\begin{array}{c}0.9 \% \text { under dabigatran versus } \\
1.8 \% \text { under warfarin }\end{array}$ \\
\hline AMPLIFY-EXT [10] & Double-blind & $\begin{array}{c}\text { Apixaban (2.5 mg twice } \\
\text { daily or } 5 \text { mg twice daily) } \\
\text { versus enoxaparin/warfarin }\end{array}$ & 12 & $\begin{array}{l}2482 \text { patients after } \\
\text { uneventful initial treatment } \\
\text { for acute DVT and/or PE }\end{array}$ & $\begin{array}{l}0.2 \% \text { under apixaban } 2.5 \mathrm{mg} \\
\text { twice daily versus } 0.1 \% \text { under } \\
\text { apixaban } 5 \mathrm{mg} \text { twice daily } \\
\text { versus } 0.5 \% \text { under placebo }\end{array}$ \\
\hline
\end{tabular}

DVT: deep vein thrombosis; PE: pulmonary embolism.

which was fatal) versus $9.3 \%$ (six out of 64 ; none of which were fatal) in the entire 6 month study period, respectively (table 1) [22-25]. It should be noted that no significant differences were observed in the risk of major bleeding in cancer patients treated with LMWH compared with those treated with warfarin after pooling of the data from these RCTs, with an overall relative risk of 1.10 (95\% CI 0.77-1.58) [26].

In all recent RCTs that compared application of NOACs to conventional LMWH/VKA therapy, 973 patients (5.1\% of the total study populations) with cancer-associated VTE were studied [27]. Pooled incidence rates of the combined end-point of major bleeding and clinically relevant non-major bleeding were 15\% (95\% CI $12-18 \%)$ for treatment with NOACs and 16\% (95\% CI 9.9-22\%) for treatment with VKA, with a corresponding risk ratio of 0.94 (95\% CI 0.70-1.3) [27]. The risk ratio for recurrent VTE was 0.66 (95\% CI 0.38-1.2) in favour of the NOACs. Notably, patients included in the LMWH/VKA or NOAC/VKA RCTs suffered from a wide range of different cancer types, and patients with advanced metastatic cancer, who are at greatest risk of bleeding complications, were relatively under-represented. Therefore, these bleeding risks must be interpreted with caution, especially if applied to individual patients.

\section{Prediction of bleeding events}

Common risk factors for bleeding events while on anticoagulant treatment include older age, female sex, history of bleeding, peptic ulcer, active cancer, hypertension, prior stroke, renal insufficiency, alcohol abuse, liver disease, targeted intensity of anticoagulant therapy and poor anticoagulant control [28-39]. The translation of these risk factors to clinical practice remains difficult, and physicians' estimates of the risk for anticoagulant-related bleeding are often inaccurate and poorly reproducible [40]. In contrast to the extensive literature in patients with atrial fibrillation, assessment of bleeding risk scores in patients with VTE is at a preliminary stage. Nonetheless, in the past two decades, some cohort studies have addressed this issue.

\section{Bleeding-prediction scores derived from VTE patient populations}

Four bleeding-prediction scores have been derived from VTE patient cohorts by NieuwenHuIs et al. [31], Kuijer et al. [32], KeAron et al. [28] and Ruíz-Giménez et al. [33]. They all comprise four to 10 different weighted variables and categorise patients into three risk categories (table 4). The first bleeding prediction rule for VTE, the so-called Nieuwenhuis score, was derived in 194 patients who were treated with either LMWH or UFH for acute VTE and followed over a period of 9 days [31]. Based on a critical review of the literature to identify risk factors for anticoagulant-associated bleeding events, KuIJER et al. [32] constructed the second published bleeding-prediction rule for VTE patients in 1999. The third rule was designed by the authors of a RCT aiming to compare low-intensity warfarin therapy with conventional-intensity warfarin therapy for the extended treatment of unprovoked VTE, and was based on ten predefined risk factors for major bleeding from the literature [28]. Risk factors for major bleeding were also evaluated in a post hoc analysis of the Registro Informatizado de la Enfermedad TromboEmbolica venosa (RIETE) registry, an international multidisciplinary project initiated in 2001 that collects patient data in a computerised registry [33]. However, the derivation of the four scores suffered from methodological flaws, including small patient samples, use of observational registries or small cohort studies with different follow-up periods, different definitions of major bleeding and inclusion bias. Consequently, attempts to 
TABLE 4 Prediction models for anticoagulation-related major bleeding in venous thromboembolism patients

\begin{tabular}{|c|c|c|c|c|c|c|c|c|c|c|c|}
\hline \multirow[t]{2}{*}{$\begin{array}{l}\text { Score name/first } \\
\text { author [ref.] }\end{array}$} & \multirow[t]{2}{*}{$\begin{array}{l}\text { Follow-up } \\
\text { duration }\end{array}$} & \multirow[t]{2}{*}{ Score } & \multicolumn{3}{|c|}{ Low-risk group" } & \multicolumn{3}{|c|}{ Intermediate-risk group" } & \multicolumn{3}{|c|}{ High-risk group } \\
\hline & & & $\begin{array}{l}\text { Score } \\
\text { points }\end{array}$ & $\begin{array}{c}\% \text { of } \\
\text { population }\end{array}$ & $\begin{array}{l}\% \text { risk of } \\
\text { major } \\
\text { bleeding }\end{array}$ & $\begin{array}{l}\text { Score } \\
\text { points }\end{array}$ & $\begin{array}{c}\% \text { of } \\
\text { population }\end{array}$ & $\begin{array}{l}\% \text { risk of } \\
\text { major } \\
\text { bleeding }\end{array}$ & $\begin{array}{l}\text { Score } \\
\text { points }\end{array}$ & $\begin{array}{c}\% \text { of } \\
\text { population }\end{array}$ & $\begin{array}{l}\% \text { risk of } \\
\text { major } \\
\text { bleeding }\end{array}$ \\
\hline Nieuwenhuis [31]" & 9 days & $\begin{array}{l}\text { WHO grade 2: } 1 \text { point; } \\
\text { WHO grade } 2 \text { or } 3: 2 \text { points; } \\
\text { Recent trauma or surgery: } \\
1 \text { point; History of bleeding } \\
\text { diathesis or body surface area } \\
<2 \mathrm{~m}^{2}: 2 \text { points each }\end{array}$ & $0-2$ & 44 & 2.3 & $3-4$ & 42 & 11 & $\geqslant 5$ & 14 & 44 \\
\hline KUIJER [32]" & 3 months & $\begin{array}{l}\text { Age }>60 \text { years: } 1.6 \text { points; } \\
\text { Female sex: } 1.3 \text { points; } \\
\text { Active malignancy: } 2.2 \text { points }\end{array}$ & 0 & $17-22$ & $0-1$ & $1-3$ & 58 & $1-2$ & $\geqslant 3$ & $20-25$ & $7-14$ \\
\hline KEARON [28]" & 12.5 months $^{\S}$ & $\begin{array}{c}\text { Age }>64 \text { years, previous stroke, } \\
\text { peptic ulcer disease, previous } \\
\text { gastrointestinal bleeds, renal } \\
\text { impairment, liver disease, } \\
\text { anaemia, thrombocytopenia, } \\
\text { diabetes mellitus, antiplatelet } \\
\text { therapy: } 1 \text { point each }\end{array}$ & 0 & 56 & $\begin{array}{c}0.4 \text { per } 100 \\
\text { patient-years }\end{array}$ & 1 & 33 & $\begin{array}{c}1.8 \text { per } 100 \\
\text { patient-years }\end{array}$ & $\geqslant 2$ & 11 & $\begin{array}{c}1.0 \text { per } 100 \\
\text { patient-years }\end{array}$ \\
\hline RuÍz-GIMÉNEZ [33]" & 3 months & $\begin{array}{l}\text { Recent major bleeding: } 2 \text { points; } \\
\text { Creatinine levels }>1.2 \mathrm{mg} \cdot \mathrm{dL}^{-1} \text { or } \\
\text { anaemia: } 1.5 \text { points each; } \\
\text { Age }>75 \text { years, active cancer or } \\
\text { PE diagnosis: } 1 \text { point each }\end{array}$ & 0 & $20-21$ & $0.1-0.3$ & $1-4$ & 74 & $2.6-2.8$ & $>4$ & $5.2-5.8$ & $6.2-7.3$ \\
\hline HAS-BLED [44] ${ }^{+}$ & 1 year & $\begin{array}{l}\text { Hypertension, abnormal renal } \\
\text { function, abnormal liver function, } \\
\text { stroke, bleeding history or } \\
\text { predisposition, labile INR, age } \\
>65 \text { years, drugs/alcohol } \\
\text { concomitantly: } 1 \text { point each }\end{array}$ & $<3$ & 95 & 1.2 & NA & NA & NA & $\geqslant 3$ & 4.6 & 7.7 \\
\hline OBRI [54] ${ }^{+}$ & 1 year & $\begin{array}{l}\text { Age }>64 \text { years, history of stroke, } \\
\text { history of gastrointestinal } \\
\text { bleeding and serious comorbidity } \\
\text { (recent myocardial infarction, } \\
\text { creatinine level }>1.5 \mathrm{mg} \cdot \mathrm{dL}^{-1} \\
\text { haematocrit }<30 \% \text {, diabetes): } \\
1 \text { point each }\end{array}$ & 0 & $30-33$ & $0.7-0.8$ & $1-2$ & $60-63$ & $8-12$ & $3-4$ & $6.1-6.8$ & $30-48$ \\
\hline
\end{tabular}

OBRI: Outpatient Bleeding Risk Index; WHO: World Health Organization; PE: pulmonary embolism; INR: international normalised ratio; NA: not applicable. \#: in original derivation and/or validation cohorts; ${ }^{\text {9: }}$ : derived in VTE patients only; ${ }^{+}$: derived in any patients; ${ }^{\text {}}$ : score for extended treatment only. 
validate these scores in external populations showed poor reproducibility and low c-statistics suggesting limited predictive value and poor reproducibility [34, 41-43]. For this reason, these scores are neither widely accepted nor applied. Prediction of bleeding in VTE patients treated with any of the NOACs, or treated for longer than 6 months, has not yet been undertaken.

\section{Bleeding-prediction scores derived from non-VTE patient populations}

In striking contrast to the limited attention paid to bleeding-prediction scores in VTE patients, multiple bleeding-prediction scores for VKA-related bleeding have been proposed and widely validated in outpatients with VKA treatment in general (Outpatient Bleeding Risk Index (OBRI)), and patients with atrial fibrillation (e.g. HAS-BLED, ATRIA and HEMORR ${ }_{2}$ HAGES) [40, 44-46]. Available evidence has led international guidelines to recommend the use of one of these scores to make an assessment of a patient's bleeding risk before treatment initiation $[47,48]$. The main reasons why scores developed for patients with other indications for anticoagulant therapy may not be applicable to the VTE population include major differences in patient demographics and underlying conditions as well as the fact that initial dosing may be different across indications. Nonetheless, the predictive accuracy of some of these bleeding-prediction scores has been evaluated in VTE patients.

Three studies analysed the predictive value of the HAS-BLED score in VTE patients. The HAS-BLED score was derived from 3978 patients in the Euro Heart Survey on atrial fibrillation and has repeatedly been shown to be predictive of bleeding in various conditions, even in patients who are not treated with any anticoagulant drugs (table 4) [44, 49-51]. The first study evaluating the HAS-BLED score in VTE patients was performed in 663 elderly patients, and reported a poor c-statistic of 0.55 [52]. A second study, performed in 515 patients with various indications for the use of VKAs, reported a c-statistic of 0.57 for the HAS-BLED score for the entire population of VKA-users, without reporting the area under the curve for the VTE population separately [43]. In the third study, the HAS-BLED score was calculated in 223 patients with PE and 314 patients with DVT, who were treated with VKAs for a period of 6 months. Major bleeding occurred in 11 out of 537 patients (5.2 per 100 patient-years) [53]. The HAS-BLED accurately differentiated between patients at non-high- and high-risk of bleeding using a cut-off of 3 points (hazard ratio for major bleeding 8.7, 95\% CI 2.7-28). The c-statistic of the continuous score for major bleeding was 0.78 , and 0.81 after exclusion of the item "labile INR". The latter is obviously relevant for potential bleeding-risk prediction of oral anticoagulants with a fixed dose such as the NOACs.

The OBRI for the prediction of bleeding in outpatients treated with VKAs was proposed by LANDEFELD et al. [54] in 1989 (table 4). Notably, VTE was the indication for VKA therapy in only 15\% of patients in this derivation cohort. The score was successfully validated in a second sample of 187 patients from the same study [54]. In addition, the OBRI was tested in 194 VTE patients who were treated with either LMWH or UFH [31]. The 9-day major bleeding risk was more pronounced in the high-risk category compared with the intermediate- and low-risk categories, $15 \%$ versus $7 \%$ and $0 \%$, respectively. Almost one decade later, the OBRI was validated in 264 outpatients who started VKA therapy for various conditions [40]. The c-statistic in the latter cohort was 0.78 . This score was finally prospectively assessed in 222 VTE patients, who were treated with LMWH followed by VKA for at least 3 months [41]. The rate of major haemorrhage per 100 patient-years was $0 \%$ in the low-risk group and $4.3 \%$ in the moderate-risk group. Only two patients were classified as high risk and neither suffered a major bleed. In both external cohorts, a c-statistic was not provided $[31,41]$.

In summary, widely validated bleeding risk scores for patients with atrial fibrillation have not been shown to consistently predict bleeding events in VTE patients, although HAS-BLED and OBRI have been reported to have useful predictive ability in at least one VTE cohort. A major limitation of all these scores is that they provide only vague definitions of the included variables and, thus, remain poorly reproducible.

\section{A practical guide for bleeding prevention in clinical practice}

General recommendations that essentially apply to all patients on anticoagulant treatment include patient education, discouraging use of concomitant anticoagulants, non-steroidal anti-inflammatory drugs or platelet-inhibitors, and adequate control of hypertension. Notably, although these measures seem likely to reduce the bleeding risk, high quality evidence underscoring this hypothesis is lacking. Only one RCT showed that an intervention comprising, among other components, extensive patient education was associated with a $50 \%$ reduction in the occurrence of major bleeding events [55].

\section{Monitoring of the anticoagulant effect in VKA treatment}

Due to the complex pharmacokinetics and pharmacodynamics of VKAs, it was expected that interventions focusing on more stringent INR control by specialised clinics or genotype-guided dosing strategies would result in less anticoagulation-associated bleeding. Indeed, computerised INR monitoring, simple two-step 
warfarin-dosing algorithms, patient self-management and patient self-testing have been shown to be associated with better VKA control and clinical outcomes, although not to a large extent [56-58]. However, two high-quality RCTs showed that use of a pharmacogenetic-based dosing strategy did not significantly reduce the risk of bleeding when compared with a clinical algorithm [59, 60]. Two other RCTs failed to show a significant difference in major haemorrhage or recurrent VTE in patients managed by a general practitioner versus a specialised anticoagulant clinic [61, 62]. Hence, despite many attempts, monitoring interventions and pharmacogenetic algorithms cannot be expected to considerably improve the safety of VKA treatment in the near future.

\section{Anticoagulant intensity and choice of drug}

Several efforts to improve the traditional combination of parenteral anticoagulant and VKAs by changing drug intensity were unsuccessful in reducing the bleeding risk: once-daily and twice-daily LMWH regimes have comparable bleeding risks [29], delaying initiation of VKA treatment until day 10 did not reduce the number of bleeding complications [63], and lowering the intensity of VKA from a target INR range of 2.0-3.0 to 1.5-2.0 was not associated with fewer bleeding events and was shown to be inferior in preventing recurrent VTE $[28,64]$.

Consequently, the current most promising measure to reduce the risk of bleeding might be a more widespread use of NOACs in clinical practice. From a recent meta-analysis, it was suggested that treatment a NOAC decreases the risk of major bleeding by $40 \%$ compared with a VKA in VTE patients, with comparable efficacy $[3-8,20]$. Importantly, a $75 \%$ relative reduction in fatal bleeding was observed. However, the number needed to treat with any one of the NOACs (instead of a VKA) to prevent one case of major bleeding was estimated at 149 , and to prevent one fatal bleeding was as high as 1111 . Moreover, and importantly, bleeding management with the new drugs is still uncertain, no specific antidotes are currently available for clinical use (phase II trials are ongoing) and routine monitoring of the anticoagulant effect of NOACs is not recommended [47]. The activated partial thromboplastin time and prothrombin time may provide a qualitative assessment of the presence of factor IIa inhibitors and factor Xa inhibitors, respectively, although these tests are not sensitive enough for quantitative assessment of the treatment effect [65]. Also, the cost-effectiveness of NOACs for VTE treatment has not yet been established.

We might also ask the question whether all NOACs are equal with regard to the bleeding risk. Head to head comparisons of NOACs have not been performed in VTE patients or in patients with atrial fibrillation. Nonetheless, when carefully evaluating the individual VTE trials, some details do catch the eye. First, because of intrinsic pharmacological dissimilarities, absorption and metabolism is different between the NOACs, as are drug-drug interactions, as described in the European Heart Rhythm Association Practical Guide on the use of NOACs in patients with non-valvular atrial fibrillation [65]. In this respect, it should be taken into account that of all the NOACs dabigatran is most dependent on renal clearance. Secondly, the meta-analysis by VAN DER HULLE et al. [20] showed relevant between study heterogeneity for the end-point of gastrointestinal bleeding, which may be due to a higher risk of gastrointestinal bleeding in patients treated with dabigatran (150 mg twice daily) compared with VKA in the RECOVER I studies (risk ratio $1.50,95 \%$ CI $0.99-2.29)$ [3, 8]. A similar effect was observed with the high dabigatran dose in the RE-LY trial $[8,66]$. Thirdly, the fact that initial treatment differs between the individual NOACs, for example starting with a higher initial oral dose for apixaban and rivaroxaban, or preceded by parenteral treatment with LMWH for edoxaban and dabigatran, may be relevant for patients in whom invasive treatment is imminent. Fourthly, although cancer patients were not explicitly excluded from the trials, only a very limited number of patients with active malignancies were actually included [3-7, 20, 27]. Hence, the safety or efficacy benefit of NOACs in these specific patients has not yet been demonstrated, and no firm conclusions can be drawn regarding differences between the individual NOACs. It should be noted that rivaroxaban was post hoc reported to have been tested in a subpopulation of "fragile VTE patients", arbitrarily defined as those aged $>75$ years, or with an estimated creatinine clearance between $30 \mathrm{~mL} \cdot \mathrm{min}^{-1}$ and $50 \mathrm{~mL} \cdot \mathrm{min}^{-1}$, or a body weight $<50 \mathrm{~kg}$ : the efficacy of this NOAC in this patient group appeared to be comparable to that in "non-fragile patients", and the safety even improved [10,67]. Even so, it is likely that very elderly patients with concomitant severe renal insufficiency and/or additional comorbidities were not sufficiently represented in the rivaroxaban or other NOAC trials.

\section{Treatment duration}

Guidelines provide recommendations on the length of standard anticoagulation, i.e. at least 3 months duration in the case of a transient risk factor for VTE and at least 6 months in the case of persistent risk factors or absence of a clear risk factor $[1,2]$. These recommendations are based on landmark trials that compared shorter (4-6 weeks) to both standard (3-6 months) and extended (6-24 months) treatment durations $[1,2,68-72]$. From these studies, it became clear that extended anticoagulation therapy with VKAs is very effective in preventing VTE recurrence, but also that the risk/benefit ratio of extended 
treatment after the first 3-6-month period is controversial because of the relatively frequent occurrence of major bleeding episodes (table 1). An additional argument against extended treatment is the reported case-fatality rate of bleeding $(13.4 \%, 95 \%$ CI 9.4-17.4\%), that exceeds that of recurrent VTE $(3.6 \%, 95 \%$ CI 1.9-5.7) $[13,19]$. Even so, the paradigm that the harms of extended treatment outweigh its benefits has begun to shift in recent years since the publication of the extended treatment studies with NOACs, in which patients were treated with a NOACs for 6-12 months after the "standard" recommended treatment period $[4,9,10]$. From these studies it became apparent that extended treatment with NOACs also effectively protects against recurrent VTE at a relatively low cost of major bleeding $(0.1-0.9 \%$ over a treatment period of 6-12 months). These findings could change clinical practice of VTE management: extended treatment after the first 6 months may become a more frequent option, especially for patients with a high recurrence risk such as those with unprovoked VTE. In this regard, the availability of well validated bleeding risk scores for long-term anticoagulation therapy seems crucial for the development of widely supported recommendations.

\section{Conclusions}

Major bleeding events may be devastating events and, if associated with VKA treatment, have been reported to have a higher case fatality rate than recurrent VTE itself. Attempts to improve the safety of VKA treatment, including stringent INR control by specialised clinics and genotype-guided dosing strategies, were largely unsuccessful. By contrast, recent studies have revealed advantages of NOACs over VKAs in terms of a reduced bleeding risk, with comparable efficacy. Differences between the individual NOACs and the limited experience with NOACs in specific patients groups underline that the choice of a specific anticoagulant drug for the first 3-6-month treatment period should depend on age, the presence of comorbidities and comedication, physicians experience, patient preferences and costs. Unfortunately, optimal risk assessment tools for both bleeding and recurrent VTE are unknown, and validated sensitive risk scores are, as yet, unavailable. Hence, one major aim for future VTE research should be the development of a validated bleeding-prediction score for VTE patients that helps decision making in clinical practice. Until then, clinicians might, in addition to their clinical judgment, decide to make use of either the HAS-BLED or OBRI bleeding-prediction scores. With the results of the extended anticoagulation trials, treatment with one of the NOACs may become a realistic option for many patients in the near future, although the decision for extended treatment should still always depend on weighing up the risk of major haemorrhage against the risk of thromboembolic recurrence in each individual patient.

\section{References}

1 Kearon C, Akl EA, Comerota AJ, et al Antithrombotic therapy for VTE disease: Antithrombotic Therapy and Prevention of Thrombosis, 9th ed: American College of Chest Physicians Evidence-Based Clinical Practice Guidelines. Chest 2012; 141: Suppl., e419S-e494S.

2 Torbicki A, Perrier A, Konstantinides S, et al. Guidelines on the diagnosis and management of acute pulmonary embolism: the Task Force for the Diagnosis and Management of Acute Pulmonary Embolism of the European Society of Cardiology (ESC). Eur Heart J 2008; 29: 2276-2315.

3 Schulman S, Kearon C, Kakkar AK, et al. Dabigatran versus warfarin in the treatment of acute venous thromboembolism. N Engl J Med 2009; 361: 2342-2352.

4 Bauersachs R, Berkowitz SD, Brenner B, et al. Oral rivaroxaban for symptomatic venous thromboembolism. N Engl J Med 2010; 363: 2499-2510.

5 Büller HR, Prins MH, Lensin AW, et al. Oral rivaroxaban for the treatment of symptomatic pulmonary embolism. N Engl J Med 2012; 366: 1287-1297.

6 Agnelli G, Buller HR, Cohen A, et al. Oral apixaban for the treatment of acute venous thromboembolism. $N$ Engl J Med 2013; 369: 799-808.

7 Büller HR, Décousus H, Grosso MA, et al. Edoxaban versus warfarin for the treatment of symptomatic venous thromboembolism. N Engl J Med 2013; 369: 1406-1415.

8 Schulman S, Kakkar AK, Goldhaber SZ, et al. Treatment of acute venous thromboembolism with dabigatran or warfarin and pooled analysis. Circulation 2014; 129: 764-772.

9 Schulman S, Kearon C, Kakkar AK, et al. Extended use of dabigatran, warfarin, or placebo in venous thromboembolism. N Engl J Med 2013; 368: 709-718.

10 Agnelli G, Buller HR, Cohen A, et al. Apixaban for extended treatment of venous thromboembolism. $N$ Engl J Med 2013; 368: 699-708.

11 Lancaster TR, Singer DE, Sheehan MA, et al. The impact of long-term warfarin therapy on quality of life. Evidence from a randomized trial. Boston Area Anticoagulation Trial for Atrial Fibrillation Investigators. Arch Intern Med 1991; 151: 1944-1949.

12 Ghate SR, Biskupiak J, Ye X, et al. All-cause and bleeding-related health care costs in warfarin-treated patients with atrial fibrillation. J Manag Care Pharm 2011; 17: 672-684.

13 Carrier M, Le Gal G, Wells PS, et al. Systematic review: case-fatality rates of recurrent venous thromboembolism and major bleeding events among patients treated for venous thromboembolism. Ann Intern Med 2010; 152 : 578-589.

14 Smith SB, Geske JB, Maguire JM, et al. Early anticoagulation is associated with reduced mortality for acute pulmonary embolism. Chest 2010; 137: 1382-1390. 
15 Hull RD, Raskob GE, Brant RF, et al. Relation between the time to achieve the lower limit of the APTT therapeutic range and recurrent venous thromboembolism during heparin treatment for deep vein thrombosis. Arch Intern Med 1997; 157: 2562-2568.

16 Kline JA, Hernandez-Nino J, Jones AE, et al. Prospective study of the clinical features and outcomes of emergency department patients with delayed diagnosis of pulmonary embolism. Acad Emerg Med 2007; 14: 592-598.

17 Brandjes DP, Heijboer H, Büller HR, et al. Acenocoumarol and heparin compared with acenocoumarol alone in the initial treatment of proximal-vein thrombosis. N Engl J Med 1992; 327: 1485-1489.

18 van Dongen CJ, van den Belt AG, Prins MH, et al. Fixed dose subcutaneous low molecular weight heparins versus adjusted dose unfractionated heparin for venous thromboembolism. Cochrane Database Syst Rev 2004; 4: CD001100

19 Linkins LA, Choi PT, Douketis JD. Clinical impact of bleeding in patients taking oral anticoagulant therapy for venous thromboembolism: a meta-analysis. Ann Intern Med 2003; 139: 893-900.

20 van der Hulle T, Kooiman J, den Exter PL, et al. Effectiveness and safety of novel oral anticoagulants compared with vitamin $\mathrm{K}$ antagonists in the treatment of acute symptomatic venous thromboembolism: a systematic review and meta-analysis. J Thromb Haemost 2014; 12: 320-328.

21 Prandoni P, Lensing AW, Piccioli A, et al. Recurrent venous thromboembolism and bleeding complications during anticoagulant treatment in patients with cancer and venous thrombosis. Blood 2002; 100: 3484-3488.

22 Meyer G, Marjanovic Z, Valcke J, et al. Comparison of low-molecular-weight heparin and warfarin for the secondary prevention of venous thromboembolism in patients with cancer: a randomized controlled study. Arch Intern Med 2002; 162: 1729-1735.

23 Lee AY, Levine MN, Baker RI, et al. Low-molecular-weight heparin versus a coumarin for the prevention of recurrent venous thromboembolism in patients with cancer. $N$ Engl J Med 2003; 349: 146-153.

24 Hull RD, Pineo GF, Brant RF, et al. Self-managed long-term low-molecular-weight heparin therapy: the balance of benefits and harms. Am J Med 2007; 120: 72-82.

25 Deitcher SR, Kessler CM, Merli G, et al. Secondary prevention of venous thromboembolic events in patients with active cancer: enoxaparin alone versus initial enoxaparin followed by warfarin for a 180-day period. Clin Appl Thromb Hemost 2006; 12: 389-396.

26 Noble SI, Shelley MD, Coles B, et al. Management of venous thromboembolism in patients with advanced cancer: a systematic review and meta-analysis. Lancet Oncol 2008; 9: 577-584.

27 van der Hulle T, den Exter PL, Kooiman J, et al. Meta-analysis of the efficacy and safety of new oral anticoagulants in patients with cancer-associated acute venous thromboembolism. J Thromb Haemost 2014; 12: 1116-1120.

28 Kearon C, Ginsberg JS, Kovacs MJ, et al. Comparison of low-intensity warfarin therapy with conventional-intensity warfarin therapy for long-term prevention of recurrent venous thromboembolism. $N$ Engl $J$ Med 2003; 349: 631-639.

29 Schulman S, Beyth RJ, Kearon C, et al. Hemorrhagic complications of anticoagulant and thrombolytic treatment: American College of Chest Physicians Evidence-Based Clinical Practice Guidelines (8th Edn). Chest 2008; 133: Suppl., 257S-298S.

30 Ageno W, Gallus AS, Wittkowsky A, et al. Oral anticoagulant therapy: Antithrombotic Therapy and Prevention of Thrombosis, 9th ed: American College of Chest Physicians Evidence-Based Clinical Practice Guidelines. Chest 2012; 141: Suppl., e44S-e88S.

31 Nieuwenhuis HK, Albada J, Banga JD, et al. Identification of risk factors for bleeding during treatment of acute venous thromboembolism with heparin or low molecular weight heparin. Blood 1991; 78: 2337-2343.

32 Kuijer PM, Hutten BA, Prins MH, et al. Prediction of the risk of bleeding during anticoagulant treatment for venous thromboembolism. Arch Intern Med 1999; 159: 457-460.

33 Ruíz-Giménez N, Suárez C, González R, et al. Predictive variables for major bleeding events in patients presenting with documented acute venous thromboembolism. Findings from the RIETE Registry. Thromb Haemost 2008; 100: $26-31$.

34 Scherz N, Méan M, Limacher A, et al. Prospective, multicenter validation of prediction scores for major bleeding in elderly patients with venous thromboembolism. J Thromb Haemost 2013; 11: 435-443.

35 Trujillo-Santos J, Nieto JA, Tiberio G, et al. Predicting recurrences or major bleeding in cancer patients with venous thromboembolism. Findings from the RIETE Registry. Thromb Haemost 2008; 100: 435-439.

36 Trujillo-Santos J, Ruiz-Gamietea A, Luque JM, et al. Predicting recurrences or major bleeding in women with cancer and venous thromboembolism. Findings from the RIETE Registry. Thromb Res 2009; 123: Suppl. 2, S10-S15.

37 van der Meer FJ, Rosendaal FR, Vandenbroucke JP, et al. Bleeding complications in oral anticoagulant therapy. An analysis of risk factors. Arch Intern Med 1993; 153: 1557-1562.

38 van der Meer FJ, Rosendaal FR, Vandenbroucke JP, et al. Assessment of a bleeding risk index in two cohorts of patients treated with oral anticoagulants. Thromb Haemost 1996; 76: 12-16.

39 White RH, Beyth RJ, Zhou H, et al. Major bleeding after hospitalization for deep-venous thrombosis. Am J Med 1999; 107: 414-424.

40 Beyth RJ, Quinn LM, Landefeld CS. Prospective evaluation of an index for predicting the risk of major bleeding in outpatients treated with warfarin. Am J Med 1998; 105: 91-99.

41 Wells PS, Forgie MA, Simms M, et al. The outpatient bleeding risk index: validation of a tool for predicting bleeding rates in patients treated for deep venous thrombosis and pulmonary embolism. Arch Intern Med 2003; 163: 917-920.

42 Low-molecular-weight heparin in the treatment of patients with venous thromboembolism. The Columbus Investigators. N Engl J Med 1997; 337: 657-662.

43 Donzé J, Rodondi N, Waeber G, et al. Scores to predict major bleeding risk during oral anticoagulation therapy: a prospective validation study. Am J Med 2012; 125: 1095-1102.

44 Pisters R, Lane DA, Nieuwlaat R, et al. A novel user-friendly score (HAS-BLED) to assess 1-year risk of major bleeding in patients with atrial fibrillation: the Euro Heart Survey. Chest 2010; 138: 1093-1100.

45 Gage BF, Yan Y, Milligan PE, et al. Clinical classification schemes for predicting hemorrhage: results from the National Registry of Atrial Fibrillation (NRAF). Am Heart J 2006; 151: 713-719. 
Fang MC, Go AS, Chang Y, et al. A new risk scheme to predict warfarin-associated hemorrhage: The ATRIA (Anticoagulation and Risk Factors in Atrial Fibrillation) Study. J Am Coll Cardiol 2011; 58: 395-401.

47 Lip GY, Andreotti F, Fauchier L, et al. Bleeding risk assessment and management in atrial fibrillation patients. Executive Summary of a Position Document from the European Heart Rhythm Association [EHRA], endorsed by the European Society of Cardiology [ESC] Working Group on Thrombosis. Thromb Haemost 2011; 106: 997-1011.

48 Wann LS, Curtis AB, Ellenbogen KA, et al. Management of patients with atrial fibrillation (compilation of 2006 ACCF/AHA/ESC and 2011 ACCF/AHA/HRS recommendations): a report of the American College of Cardiology/ American Heart Association Task Force on practice guidelines. Circulation 2013; 127: 1916-1926.

49 Apostolakis S, Lane DA, Guo Y, et al. Performance of the HEMORR(2)HAGES, ATRIA, and HAS-BLED bleeding risk-prediction scores in patients with atrial fibrillation undergoing anticoagulation: the AMADEUS (evaluating the use of SR34006 compared to warfarin or acenocoumarol in patients with atrial fibrillation) study. J Am Coll Cardiol 2012; 60: 861-867.

50 Apostolakis S, Lane DA, Guo Y, et al. Performance of the HEMORR2HAGES, ATRIA, and HAS-BLED bleeding risk-prediction scores in nonwarfarin anticoagulated atrial fibrillation patients. J Am Coll Cardiol 2013; 61: 386-387.

51 Roldán V, Marín F, Fernández H, et al. Predictive value of the HAS-BLED and ATRIA bleeding scores for the risk of serious bleeding in a "real-world" population with atrial fibrillation receiving anticoagulant therapy. Chest 2013; 143: 179-184.

52 Poli D, Antonucci E, Testa S, et al. The predictive ability of bleeding risk stratification models in very old patients on vitamin $\mathrm{K}$ antagonist treatment for venous thromboembolism: results of the prospective collaborative EPICA study. J Thromb Haemost 2013; 11: 1053-1058.

53 Abstracts of the XXIV Congress of the International Society on Thrombosis and Haemostasis. June 29-July 4, 2013. Amsterdam, The Netherlands. J Thromb Haemost 2013; 11: Suppl. 2, 1-1322.

54 Landefeld CS, Goldman L. Major bleeding in outpatients treated with warfarin: incidence and prediction by factors known at the start of outpatient therapy. Am J Med 1989; 87: 144-152.

55 Beyth RJ, Quinn L, Landefeld CS. A multicomponent intervention to prevent major bleeding complications in older patients receiving warfarin. A randomized, controlled trial. Ann Intern Med 2000; 133: 687-695.

56 Poller L, Keown M, Ibrahim S, et al. An international multicenter randomized study of computer-assisted oral anticoagulant dosage vs. medical staff dosage. J Thromb Haemost 2008; 6: 935-943.

57 Heneghan C, Ward A, Perera R, et al. Self-monitoring of oral anticoagulation: systematic review and meta-analysis of individual patient data. Lancet 2012; 379: 322-334.

58 Kim YK, Nieuwlaat R, Connolly SJ, et al. Effect of a simple two-step warfarin dosing algorithm on anticoagulant control as measured by time in therapeutic range: a pilot study. J Thromb Haemost 2010; 8: 101-106.

59 Anderson JL, Horne BD, Stevens SM, et al. Randomized trial of genotype-guided versus standard warfarin dosing in patients initiating oral anticoagulation. Circulation 2007; 116: 2563-2570.

60 Kimmel SE, French B, Kasner SE, et al. A pharmacogenetic versus a clinical algorithm for warfarin dosing. $N$ Engl J Med 2013; 369: 2283-2293.

61 Matchar DB, Samsa GP, Cohen SJ, et al. Improving the quality of anticoagulation of patients with atrial fibrillation in managed care organizations: results of the managing anticoagulation services trial. Am J Med 2002; 113: 42-51.

62 Wilson SJ, Wells PS, Kovacs MJ, et al. Comparing the quality of oral anticoagulant management by anticoagulation clinics and by family physicians: a randomized controlled trial. CMAJ 2003; 169: 293-298.

63 Leroyer C, Bressollette L, Oger E, et al. Early versus delayed introduction of oral vitamin $\mathrm{K}$ antagonists in combination with low-molecular-weight heparin in the treatment of deep vein thrombosis. A randomized clinical trial. The ANTENOX Study Group. Haemostasis 1998; 28: 70-77.

64 Ridker PM, Goldhaber SZ, Danielson E, et al. Long-term, low-intensity warfarin therapy for the prevention of recurrent venous thromboembolism. N Engl J Med 2003; 348: 1425-1434.

65 Heidbuchel H, Verhamme P, Alings M, et al. European Heart Rhythm Association Practical Guide on the use of new oral anticoagulants in patients with non-valvular atrial fibrillation. Europace 2013; 15: 625-651.

66 Sipahi I, Celik S, Tozun N. A comparison of results of the US Food and Drug Administration's mini-sentinel program with randomized clinical trials: the case of gastrointestinal tract bleeding with dabigatran. JAMA Intern Med 2014; 174: 150-151.

67 Prins $\mathrm{MH}$, Lensing AW, Bauersachs $\mathrm{R}$, et al. Oral rivaroxaban versus standard therapy for the treatment of symptomatic venous thromboembolism: a pooled analysis of the EINSTEIN-DVT and PE randomized studies. Thromb J 2013; 11: 21

68 Kearon C, Ginsberg JS, Anderson DR, et al. Comparison of 1 month with 3 months of anticoagulation for a first episode of venous thromboembolism associated with a transient risk factor. J Thromb Haemost 2004; 2: 743-749.

69 Kearon C, Gent M, Hirsh J, et al. A comparison of three months of anticoagulation with extended anticoagulation for a first episode of idiopathic venous thromboembolism. N Engl J Med 1999; 340: 901-907.

70 Agnelli G, Prandoni P, Santamaria MG, et al. Three months versus one year of oral anticoagulant therapy for idiopathic deep venous thrombosis. Warfarin Optimal Duration Italian Trial Investigators. N Engl J Med 2001; 345: $165-169$

71 Agnelli G, Prandoni P, Becattini C, et al. Extended oral anticoagulant therapy after a first episode of pulmonary embolism. Ann Intern Med 2003; 139: 19-25.

72 Schulman S, Rhedin AS, Lindmarker P, et al. A comparison of six weeks with six months of oral anticoagulant therapy after a first episode of venous thromboembolism. Duration of Anticoagulation Trial Study Group. $N$ Engl J Med 1995; 332: 1661-1665. 